\title{
HATCH-OUT ANALYSIS AND REPEATABILITY ESTIMATES OF COMMON HATCHABILITY PROBLEMS IN ISA-BROWN BREEDER STOCK
}

\author{
*Fayeye T. R. and Olapade A. A. \\ Department of Animal Production, Faculty of Agriculture, University of Ilorin, P.M.B. 1515, llorin, \\ Nigeria. \\ *Corresponding Author: fayetiro@yahoo.com Phone: 234-(0)8060395678
}

\begin{abstract}
Six thousand and three hundred (6,300) sampled hatchable eggs (from a total of 68,130 eggs) produced in two commercial farms were used to evaluate hatchout performance and repeatability of some common hatchability problems in 38-41 weeks old Isa-Brown hens. Fertility, hatchability of total egg set and hatchability of fertile eggs were generally high (>80\%) for eggs from the two farms. There was significant difference $(p<0.05)$ between the two farms in the magnitude of hatchability problems at the early (1-7 days) and late (15-17 days) stages of embryonic development. Hatchability problems were higher for eggs obtained from farm $A B(16.89 \%)$ than for eggs obtained from farm AA (11.87\%). The trio of early post fertility mortality, piped, and dead-in-shell were the most important hatchability problems in the two farms. The estimates of repeatability of hatchability problems were generally high (66-98\%). Repeatability estimates obtained for early and late embryonic stages were higher than that obtained for the midembryonic stage. Results obtained from this study showed that farms source of hatchable eggs has effect on the type and magnitude of reproductive failures that occurred during incubation. The high repeatability of hatchability problems at the early and late embryonic stages suggest a high probability of reproductive failure at the early and late stages of embryonic development in the future except corrective breeding and management strategies are put in place.
\end{abstract}

Keywords: Hatch-Out Analysis, Repeatability, Fertility, Mortality and Hatchability

\section{INTRODUCTION}

Fertility and hatchability are the major determinants of profitability in the hatchery enterprise and therefore must be given appropriate attention in breeding programs for commercial layers (Peters et al., 2008 and Cavero et al., 2011). Hatchability comprises of several sub-traits which are susceptible to genetic and environmental factors arising from various sources (Heier and Jarp, 2001; Orumuyi et al., 2007; Wolc and Olori 2009; Wondmeneh, et al., 2011).

A breakout analysis of hatching eggs is done to evaluate the breeder flock's progress with respect to fertility and hatchability. It is an absolutely essential diagnostic tool for separating and quantifying the problem areas that cause low hatchability (Mauldin, 2003). It allows the hatchery manager to determine at what age an embryo may have died and therefore the cause of any poor hatchability. Wilson (2004) observed that analysis of hatch debris produces valuable information that could help solve hatchery and breeder flock problems, or improve hatchability and profitability. 
Repeatability is the proportion of total variance in multiple measurements of a trait that is due to difference among individuals. Falconer and Mackay (1997) stated that repeatability predicts future performance from past records and give light on the nature of environmental variance. It is a useful tool for quantifying Fayeye \& Olapade, 2013

the extent to which an individual's performance or behaviour remain consistent over time (Lesssells and Boag, 1987; Boake, 1989; Harper, 1994; Dohm, 2002). High repeatability indicates that individuals tend to perform consistently and therefore, fewer records would be required to adequately characterize the inherent ability of the animal for that trait (Akpa et al., 2008). The objective of this study was carry out an hatch-out analysis and repeatability of common hatchability problems in Isa- Brown breeders flock.

\section{MATERIALS AND METHODS}

Six thousand and three hundred (6,300) were sampled from a total of 68,130 hatchable IsaBrown breeder eggs from two commercial farms tagged XAA and XAB, respectively. The IsaBrown breeder hens that produced the eggs were 38 to 41 weeks old. The eggs were collected during the raining season of 2011. Both farms XAA and XAB are located in the Rainforest agroecological zone of Nigeria. Farm XAA is located at llemona, Kwara State $\left(8^{\circ} 12^{\prime} 0^{\prime \prime}\right.$ North, $4^{\circ} 47^{\prime}$ $0^{\prime \prime}$ East and elevation of $\left.415 \mathrm{~m}\right)$, while farm XAB is located at Omi Adio-lbadan, Oyo State $\left(7^{\circ} 23^{\prime}\right.$ 38" North, $3^{\circ} 45^{\prime} 13^{\prime \prime}$ East and elevation of about $275 \mathrm{~m}$ ). The two farms are about $150 \mathrm{~km}$ apart (Map data, 2013). The eggs collected from each farm were fumigated and then stored for 5 days in the cold room at $\approx 16.670 \mathrm{C}$. The eggs were then pre-warmed for 8 hours before loading into Petersime incubator. Optimal incubation temperature and relative humidity conditions were maintained (Petersime incubators and Hatcheries, 2010). Fertility of eggs was determined using a total sample of 4,500 eggs (i.e. 1,500 eggs from top, middle and lower parts of the setter) for eggs obtained from farm XAA and a sample of 1,800 eggs (i.e. 600 eggs from the top, middle and lower parts of the setter) for eggs obtained from farm XAB. The sampling of eggs was done in three batches. Eggs were transferred to hatcher on the 18th day of incubation and on the 21st day of incubation the chicks were pulled out. Breakout analysis was done in two stages (at candling and after hatching). The breakout analysis of culled eggs at candling was done by visual appraisal as described by Lourens et al. (2006). Hatch-day breakout analysis of unhatched eggs was conducted at the end of hatching process. The observation made on unhatched eggs and defects observed on unfit chicks were recorded using the procedure given by Wilson (2004). Observed defects were further streamlined to three embryonic stages at which the problem occurred (Abudabos, 2010). Data obtained from the incubation process was used to determine indices of reproductive efficiency as described by (Mauldin, 2003):

i. $\%$ Fertility $=100$-(no of infertile $\div$ sample size) $\times 100$

ii. $\%$ Hatchability $=($ no hatched $\div$ no set $) \times 100$ 
iii. $\%$ Hatch of fertile $=($ Hatchability $\div$ fertility $) \times 100$

iv. $\quad \%$ estimated Hatchability $=100-\%$ Reproductive failures

v. Sample index $=\%$ Estimated Hatchability $-\%$ Hatchability.

The data obtained from breakout analysis of culled and unhatched eggs were subjected to one way analysis of variance. The mathematical model for estimating the variance components was as follow:

$Y i j=\mu+b i+e i j$

Where $Y_{i j}$ is the jth record obtained in the ith batch.

$\mathrm{bi}=$ Fixed effect of ith batch

eij = Random error

$\mu=$ common mean.

Estimates of repeatability of common hatchability problems in Isa-Brown breeders flock were obtained using the formula below (Becker, 1992).

$R=\delta 2 w \div \delta 2 w+\delta 2 e$

Where $R$ = estimate of repeatability

$\delta 2 w=$ variance due to the fixed effect of batch

$\delta 2 e=$ within batch variance

RESULTS AND DISCUSSION

The total number of egg set and the number of sampled eggs from the two farms are presented in table 1. The sampled index ranged from 1.2-2.2. Fertility and hatchability performance of eggs from Isa-Brown breeder stock in the two farms are presented in table 2. The fertility (\%), hatchability of total egg set and Hatchability of fertile eggs were generally high $(>80 \%)$ for eggs obtained from the two farms. Fertility and hatchability were $95.8 \%$ and $86.8 \%$ for farm $\mathrm{XAA}$ and $88.4 \%$ and $81.0 \%$ for farm $\mathrm{XAB}$, respectively. Table 3 showed the hatchability problems for 6,300 sampled eggs obtained from the two farms (i.e. farms XAB and XAA). There was significant difference $(p<0.05)$ between the two farms in the occurrence of hatchability problems at the early (1-7 days of incubation) and late (15-17 days of incubation) stages of embryonic development of Isa-Brown breeder chicks. Hatchability problems were higher for eggs obtained at farm XAB (16.89\%) than for eggs obtained from farm XAA (11.87\%). Early post fertility mortality as well as piped, and dead-in-shell were the most important problems in the two 
farms. Exploders (bangers), Unhealed navels, Small chicks were specifically important problems observed on eggs obtained from XAB Farm.

Figure 1 showed hatchability problem grouped into embryonic developmental stages for the two farms. The observed reproductive failures follow the same trend for the two farms. Most of the hatchability problems occurred at the late embryonic stage (i.e. 15-17 days of incubation). Hatchability problems were $4.67 \%, 0.80 \%$ and $6.40 \%$ and $4.67 \%, 1.17 \%$ and $11.06 \%$ for eggs obtained at farms XAA and XAB, respectively at the first (1-7 days), second (8-14 days) and third (15-21 days) embryonic stage, respectively.

Repeatability Estimate obtained for hatchability problems is presented in table 4 . The estimates of repeatability of hatchability problem were generally high (66-98\%). Repeatability estimates obtained at the early and late embryonic stages were higher than that obtained for the midembryonic stage.

Sample index in this study fell within the acceptable range of 3.0 zero and thus validating the results of the breakout analyses of sampled egggs in the two farms. Mauldin (2003) submitted that it would be incorrect to make corrective management changes when the sample index is high (greater than 3). The fertility and hatchability in the present study were slightly lower than that reported Alsobayel and Albadry (2012) for Saudi Arabian Baladi and Leghorn breeds but close to that reported by Ali et al. (2012) for Egyptian Inshas and Dokki4 developed strains.

The fertility and hatchability of eggs from the two farms were higher than what was gotten by Abudabos (2010) in his work on Cobb breeder strain. Cavero et al. (2011) also recorded a lower fertility and hatchability from their study 12,742 fully pedigreed hens of two pure-bred commercial White Leghorn. The higher hatchability percentage obtained when the calculation was based on fertile eggs agreed with the result of Abudabos (2010) on Ross and Cobb broiler breeder strains. The higher hatchability of total egg obtained from farm XAA than that of farm XAB seem to reflect the breeding practices in the two farms. Farm XAA produce its fertile eggs through artificial insemination while farm $X A B$ produced its fertlie eggs through natural mating.

The observed difference between the two farms in the magnitude of hatchability problems showed that location has significant effect on hatchability and fertility performances of Isa- Brown breeder eggs. De Smit et al., (2006) reported that embryonic development is a dynamic process determined by the genetic background of the organism and also by the environment in which it develops. Heier and Jarp (2001) reported from data obtained from 112 Ross 208 breeder flocks in 39 breeding farms between 1996 and 1998 in Norway that hatchability was influenced by the storage time from lay until incubation, method used for disinfecting the hatching eggs, production year and whether the farmers delivered floor eggs. Other factors such as temperature, humidity, ventilation, position, egg turning and candling and variation in feed composition have resulted in variation in hatchability (Mussaddeq et al., 2002).

Hatchability problems resulting from early dead embryo suggested a failure of the embryo to resume development after storage and transfer to the setter (North and Bell, 1990). Abudabos (2010) stated that late dead embryonic mortality represents death due to abnormal positioning, 
complications in physiological changes, lethal genes and death due to chick failure to penetrate egg at hatching. The present study therefore suggest that most of the loss of hatchable eggs in the two farms can be traced to managements, genetic defects and changes associated with physiological complication in the last phase (15-21 days) of incubation. The low hatch-out problems that occurred during the mid-embryonic stage for eggs obtained from the two farms was in agreement with the result obtained by Abudabos (2010). Mid-dead embryo is usually related to nutritional deficiencies in the broiler breeder diet or embryonic abnormalities (Abudabos, 2010), therefore the obseved low hatch-out defects at the mid-phase of embryonic development in this suggests good nutritional management in the two farms.

The estimates of repeatability obtained in the present study suggest that reproductive failures observed in the early and late embryonic stages in the present study might reoccur in future except improved breeding and management strategies are employed by the two farms.

\section{CONCLUSION AND RECOMMENDATIONS}

The implication of the present study is that farm source of hatchable eggs have significant effect on fertility and hatchability traits. The present study further suggest that most of the loss of hatchable eggs in the two farms can be traced to managements, genetic defects and changes associated with physiological complication in the last phase (15-21 days) of incubation. Repeatability estimates obtained for hatchability problems at the early and late embryonic stages suggest a high probability of future occurrence except corrective breeding and management strategies are put in place.

\section{REFERENCES}

Abudabos, A. (2010). The Effect of Broiler Breeder Strain and Parent Flock Age on Hatchability and Fertile Hatchability. International Journal of Poultry Science 9 (3): 231-235.

Akpa, G. N.; Kaye, J.; Adeyinka, I. A. and Kabir, M. (2008). The Relationships between Laying Age and Repeatability of Egg Quality Traits in Japanese Quails (Coturnix coturnix japonica). International Journal of Poultry Science 7 (6): 555-559.

Ali, M. N.; Hassan, M. S.; Abd El-Ghany, F. A. and Awade, N. B. (2012). Using Natural Antioxidants with or Without Sulphate to Improve Productive and Reproductive Performance of Two Local Strains at Late Egg Production Period. International Journal of Poultry Science 11 (4): 269-282.

Alsobayel, A. A. and Albadry, M. A. (2012). Effect of age and sex ratio on fertility and hatchability of baladi and leghorn laying hens. J. Anim. Plant Sci. 22(1):15-19.

Becker, W. A. (1992). A Manual of Quantitative Genetics. Academic Enterprises, Pullman.

Boake, C. R. B. (1989) Repeatability: Its role in evolutionary studies of mating behaviour. Evol Ecol., 3, 173-182.

Cavero, D.; Schmutz, M.; Icken, W. and Preisinger, R. (2011). Improving hatchability in white egg layer strains through breeding. Lohmann information. Vol. 46 (1), $44-54$. 
De Smit, L., Bruggeman, V.; Tona, K.; Debonne, M. and Onagbesan, O. (2006). Embryonic development plasticity of the chick: Increased $\mathrm{CO} 2$ during early stages of incubation changes the developmental trajectories during prenatal and postnatal growth. Comp. Biochem. Physiol. Part A: Mol. Integr. Physiol., 145: 166-175.

Dohm, M. R. (2002). Repeatability estimates do not always set an upper limit to heritability. Funct. Ecol. 65,273-280.

Falconer, D. S. and Mackay, T. F. C. (1997). An Introduction to Quantitative Genetics. Addison Wesley Longman Ltd. UK.

Harper, D. G. C. (1994). Some comments on the repeatability of measurements, Ringing and Migration 15 (2):84-90.

Heier, J. and Jarp, B. T. (2001). An Epidemiological Study of the Hatchability in Broiler Breeder Flocks. Poultry Science 80:1132-1138

Lesssells, C. M. and Boag, P. T. (1987). Unrepeatable repeatabilities: a common mistake. Auk, 104, 116-121.

Lourens, A. R.; Molenaar, H.; Van Den Brand, M. J.; Heetkamp, R.; Meijerhof and Kemp, B. (2006). Effect of egg size on heat production and the transition of energy from egg to hatchling. Poult. Sci., 85: 770-776.

Map data, (2013). http://www.gomapper.com/travel/directions-from/ilemona-to-ibadan-oyo-nigeria.html

Mauldin, J. M. (2003). Breakout Analyses Guide for Hatcheries. The Poultry Site. http://www.thepoultrysite.com/articles/160/breakout-analyses-guide-for-hatcheries

Mussaddeq, Y.; Daud, S. and Akhtar, S. (2002). A study on the laying performance of cross (FAY x RIR) chicken under different plans of feeding. Int. J. Poult. Sci., 1: 188-192.

North, M. O. and Bell, D. D. (1990). Commercial Chicken Production Manual. 4th Edn. Avi, New York.

Orunmuyi, M.; Oni, O. O.; Adeyinka, I. A. and Asiribo, O. E. (2007). Genetic parameter estimates for plasma alkaline phosphatase activity and reproductive traits in two strains of Rhode Island chickens. Asian J. Anim. Sci., 1: 76-81.

Peters, S. O.; Shoyebo, O. O.; Ilori, B. M.; Ozoje, M. O.; Ikeobi, C. O. N. and Adebambo, O. A. (2008). Semen quality traits of seven strains of chickens raised in the humid tropics. Int. J. Poult. Sci., 7: 949-953.

Petersime incubators and Hatcheries (2010). Conventional series- Multi- and single stage incubators. Petersime nv Centrumstraat 125 - 9870 Zulte (Olsene) - Belgium. www.petersime.com

Wilson, H. R. (2004). Hatchability Problem Analysis. http://www.natureform.com/kb/index.php?article=1011

Wolc, A. and Olori, V. E. (2009). Genetics of hatchability-egg quality from the perspective of a chick. http://www.cabdirect.org/abstracts/20103247216.html

Wondmeneh, E.; Dawud, I. and Adey, M. (2011). Comparative Evaluation of Fertility and Hatchability of Horro, Fayoumi, Lohmann Silver and Potchefstroom Koekoek Breeds of Chicken. Asian Journal of Poultry Science, 5: 124-129. 
Table 1: Total number of egg set and sampled from eggs collected at XAB and XAA

\begin{tabular}{llllll}
\hline Farm & Total egg set & \multicolumn{2}{l}{ No. of eggs Sampled } & & \\
& & 1st Batch & $2^{\text {nd }}$ Batch & 3rd Batch & Total \\
& & & & & \\
\hline XAA & 57,600 & 1500 & 1500 & 1500 & 4,500 \\
XAB & 10,530 & 600 & 600 & 600 & 1,800 \\
TOTAL & 68,130 & 2100 & 2100 & 2100 & 6,300 \\
\hline
\end{tabular}

$\mathrm{XAA}, \mathrm{XAB}$ represent the two commercial farms.

Table 2: Fertility and Hatchability data obtained from 6,300 sampled eggs from XAB and XAA

\begin{tabular}{llllllllll}
\hline Farm & Infertile & UHE & HUC & HNC & $\%$ Fer & $\% \mathrm{H}_{\mathrm{E}}$ & $\% \mathrm{H}_{\mathrm{A}}$ & $\% \mathrm{H}_{\mathrm{F}}$ & Sample index \\
\hline XAA & 187 & 407 & 127 & 3779 & 95.8 & 88.0 & 86.8 & 90.6 & 1.2 \\
XAB & 209 & 133 & 171 & 1,287 & 88.4 & 83.2 & 81.0 & 91.6 & 2.2 \\
TOTAL & 396 & 540 & 298 & 5066 & 92.1 & 85.6 & 83.9 & 91.1 & 1.7
\end{tabular}

$\mathrm{XAA}, \mathrm{XAB}$ represent the two commercial farms. UHE, HUC and HNC, represent Unhatched eggs, Hatched Unfit Chicks and Hatched Normal Chicks, respectively. $\% F e r, \% \mathrm{HE}_{E}, \% \mathrm{H}_{\mathrm{A}}$ and $\% \mathrm{HF}_{\mathrm{F}}$, represent percentage of fertile eggs, estimated hatchability, Actual hatchability of set eggs and Hatchability of fertile eggs, respectively.

Table 3: Hatchability problems obtained using 6,300 sampled eggs from two commercial farms

\begin{tabular}{l|ll}
\hline \multirow{2}{*}{ Observed Features } & \multicolumn{2}{|c}{$\%$ of total sample } \\
\cline { 2 - 3 } & Farm XAA & Farm XAB \\
\hline Eye Abnormalities & 0.4 & 0.2 \\
Exploders(Bangers) & 0.5 & 1.4 \\
Crossed beak, Twisted beak & 0.1 & 0.0 \\
Early mortality & 1.9 & 1.7 \\
Bared head, Swollen head and neck & 0.0 & 1.1 \\
Malformation & 0.3 & 0.2 \\
Crooked toes & 0.0 & 0.1 \\
Dead in germ & 1.4 & 0.6 \\
Bent bones, Shortened large bones & 0.4 & 0.4 \\
Mal-positioned & 0.2 & 0.2 \\
Broad piped area, membrane incompletely retracted & 0.5 & 0.5 \\
Bloody navels & 0.2 & 0.2 \\
Piped, Full time embryo, dead in shell & 2.7 & 1.7 \\
Unhealed navels, Wet odorous & 0.2 & 1.1 \\
Unhealed navels, dry rough down feathers & 0.4 & 2.6 \\
Not piped, Full time embryo, Large yolk sac & 0.7 & 0.7 \\
Shell partially piped, embryo alive or dead & 0.8 & 0.6 \\
Early hatched chicks, thin and noisy & 0.1 & 0.4 \\
Sticky chicks, Stuck in shell, dry chicks & 0.2 & 0.3 \\
Small Chicks & 0.2 & 1.1 \\
Weak Chicks & 0.4 & 2.0 \\
\hline Total & 12.0 & 16.8 \\
\hline
\end{tabular}


Fig 1: Hatchability problems grouped into embryonic developmental stages in two commercial Farms in Nigeria

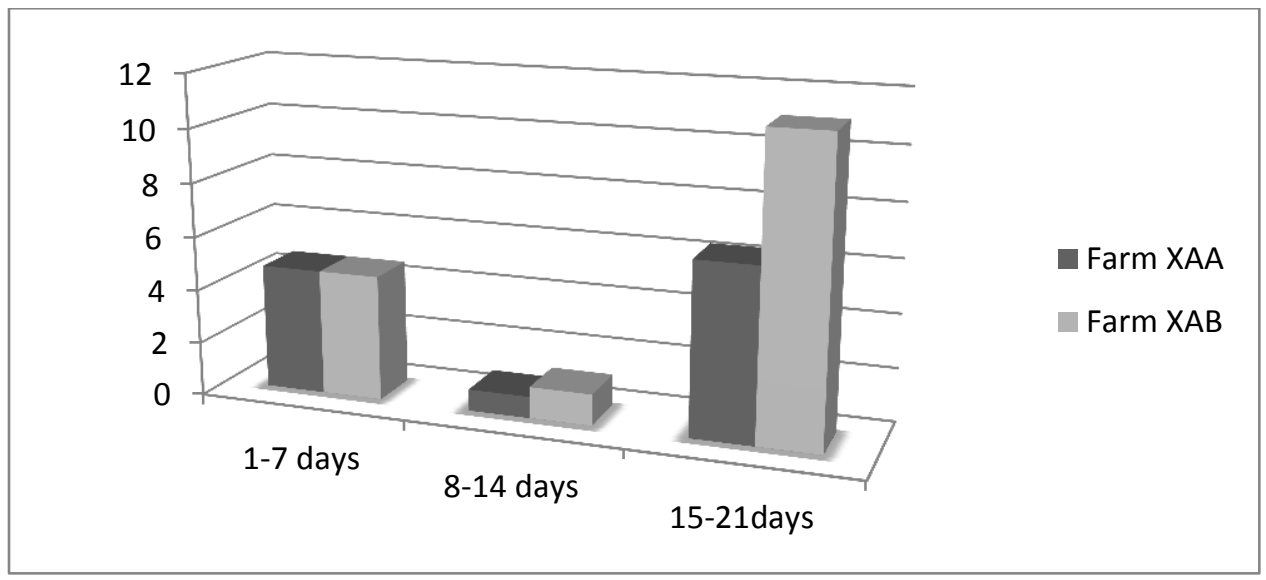

Table 4: Repeatability estimates of hatchability problems for 6,300 sampled eggs from two commercial farms in Nigeria

\begin{tabular}{lll}
\hline Hatchability problems & Error Mean Square & Reapeatability \\
\hline 1-7 days & 9.5 & 0.98 \\
8-14days & 5.5 & 0.66 \\
15-21 days & 40.7 & 0.91 \\
\hline
\end{tabular}

